\title{
Uma introdução à história da gramática em língua portuguesa
}

\author{
An introduction to the history of grammar in Portuguese
}

\author{
Mariane Rezende Melazo ${ }^{1}$ \\ Leandro Silveira de Araujo ${ }^{2}$
}

Resumo: Orientados pelo conceito de norma linguística e suas manifestações (COSERIU, 1962; ALÉONG, 2011), voltamo-nos ao estudo do processo da produção gramatical da língua portuguesa a fim de identificar os instrumentos de gramatização desse idioma, seu comportamento e características textuais e extratextuais. Para tanto, recorremos ao acervo online de bibliotecas de centros universitários no Brasil, Portugal, Angola e Moçambique compondo um corpus de 161 gramáticas. Entre outros, foi possível observar que, apesar de o início da produção de gramáticas dar-se em Portugal e se restringir ao país até início do século XIX, o Brasil apresenta-se como principal produtor de gramáticas desde o Séc. XIX. Por sua vez, os países africanos parecem estar ainda hoje à margem na produção gramaticógrafa da língua portuguesa. A pouca representatividade da autoria feminina e a pouco expressividade da abordagem descritiva na gramática escolar foram outros dados que nos ajudaram a refletir sobre a normatização da língua portuguesa e caminhos futuros para os estudos gramaticais. Essas e outras informações evidenciam que, além de esboçar os caminhos da gramaticografia do português, este estudo abre portas para abordagens futuras que permitam entender ainda mais como de deu o processo de normatização do português e quais demandas vigoram atualmente.

Palavras-chave: Norma linguística. Língua portuguesa. Gramaticografia. Historiografia linguística.

Abstract: Guided by the concept of linguistic norm and its manifestations (COSERIU, 1962; ALÉONG, 2011), we turn to the study of the process of grammatical production of the Portuguese language in order to identify the grammatical instruments of that language, their behavior and textual and extratextual characteristics. To do so, we used the online collection of libraries from university centers in Brazil, Portugal, Angola and Mozambique, composing a corpus of 161 grammars. Among others, it was possible to observe that, despite the beginning of grammar production taking place in Portugal and being restricted to the country until the beginning of the 19th century, Brazil has been the main producer of grammars since the 19th century. However, African countries still seem to be on the sidelines today in the grammatical production of the Portuguese language. The low representativeness of female authorship and the low expressiveness of a descriptive approach in school grammar were other data that helped us to reflect on the standardization of the Portuguese language and future paths for grammatical studies. This and other information shows that, in addition to sketching the paths of Portuguese grammar, this study opens doors for future approaches that allow us to understand even more how the Portuguese standardization process took place and what demands are currently in force.

Keywords: Linguistic norm. Portuguese. Gramaticography. Linguistic historiography.

\footnotetext{
${ }^{1}$ Universidade Federal de Uberlândia, Instituto de Letras e Linguística, Uberlândia, MG, Brasil. Foi bolsita CNPq de Iniciação Científica. Endereço eletrônico: marianemelazo@ hotmail.com.

${ }^{2}$ Universidade Federal de Uberlândia, Instituto de Letras e Linguística, Uberlândia, MG, Brasil. Endereço eletrônico: araujoleandrosilveira@gmail.com.
} 


\section{Língua, norma e gramatização}

A língua possui caráter social e compartilha com o indivíduo todos os momentos de sua experiência de vida. Ao nascer, o ser humano recebe um nome e é imediatamente inserido em uma comunidade específica de fala, a qual servirá de alicerce para as experiências futuras, a formação de vínculos sociais e afetivos, além de moldar sua visão de mundo. Como resultado da capacidade sociocognitiva do indivíduo na aquisição da linguagem, o falante revela-se um poliglota da própria língua, sendo capaz por si só de diferenciar o que cabe em um momento específico ou não (BAGNO, 2014).

Essa habilidade relaciona-se diretamente com o conceito de norma linguística, pois, conforme nos explica Coseriu (1962), essa norma configura-se como

[...] un sistema de realizaciones obligadas, de imposiciones sociales y culturales, y varía según la comunidad. Dentro de la misma comunidad lingüística nacional $\mathrm{y}$ dentro del mismo sistema funcional pueden comprobarse varias normas (lenguaje familiar, lenguaje popular, lengua literaria, lenguaje elevado, lenguaje vulgar, etcétera) (COSERIU, 1962, p. $98)^{3}$

A norma seria então um conjunto de realizações concretas e de caráter coletivo da língua. Ao enunciar, os sujeitos se orientam e reproduzem normas socialmente instituídas entendidas como um sistema de regras negociado em sociedade. Dessa forma, o conceito traz em si uma realização coletiva, de tradição e de repetição de modelos anteriores, desfavorecendo o que é individual ao falante (COSERIU, 1962). Assim, a língua não somente interfere no meio social, mas também é formatada por ele, instaurando uma relação recíproca (BAGNO, 2014).

Aléong (2011) explica que não há somente uma norma única, mas inúmeras em função de todas as coerções possíveis:

Nesta concepção de sociedade [heterogênea], as normas sociais ou regras do comportamento são variadas e relativas. Variadas porque os agrupamentos constitutivos da sociedade também são variados, e relativas porque os juízos de valor só têm significação em relação ao grupo ou ao conjunto de referência no qual se situam os indivíduos. (ALÉONG, 2011, p. 145)

\footnotetext{
3 Tradução nossa: "um sistema de realizações obrigatórias, de imposições sociais e culturais, e que varia conforme a comunidade. Dentro da mesma comunidade linguística nacional e dentro do mesmo sistema funcional podem ser comprovadas varias normas (linguagem familiar, linguagem popular, língua literária, linguagem elevada, linguagem vulgar etc)" (COSERIU, 1962, p. 98).
} 
No entanto, o termo 'norma' envolve outros sentidos em nossa sociedade. Talvez o mais habitual atrelado a ela corresponda ao traço normativo que pode assumir. Desse modo, opõem-se a 'norma normal' à 'norma normativa'. Esta última seria um 'ideal definido por julgamentos de valor e pela presença de um elemento de reflexão consciente por parte das pessoas interessada". Por sua vez, a 'norma normal' seria definida "no sentido matemático de frequência real dos comportamentos observados" (ALEONG, 2011, p. 257). Desse modo, o que é 'normal' comporta o costume, o que é habitual e comum em uma comunidade de fala. Já o sentido de normativo liga-se diretamente ao de regras decretadas, remetendo a um sistema ideal de valores que determina o que é imposto dentro da comunidade.

É nesse amplo cenário de discussão que envolve a relação do homem com a linguagem em forma de instrumentos normativos (gramáticas) é que se insere a proposta deste trabalho, de identificar quais são e como foram compostas as gramáticas da língua portuguesa ao longo da história. Isso para refletirmos sobre o modelo normativo ao que a gramaticografia lusófona mais se aproximou no decorrer do tempo.

Em outros termos, o presente estudo fundamenta-se na compilação de gramáticas da língua portuguesa com o propósito de conhecer as características gerais que configuram o processo de gramatização nessa língua, destacando seu processo de construção ao longo do tempo, a circulação entre países falantes de português, algumas nuances da produção gramatical e sua aproximação ao ensino. Nesse sentido, a discussão aqui levantada ocorre no bojo do estudo da norma linguística, na relação língua e sociedade.

Mais pontualmente, foram objetivos deste estudo (i) identificar instrumentos de gramatização da língua portuguesa ao longo da história; (ii) descrever características dos instrumentos de gramatização da língua portuguesa; (iii) categorizar os instrumentos de gramatização em momento histórico, origem geográfica, referencial teórico-metodológico, objetivo etc; (iv) delinear a gramaticografia da língua portuguesa. Desse modo, além de identificar e discutir distintos tipos de gramática, nossos dados ajudam a compreender e a delinear o processo gramaticográfico e o modo gradativo como se deu entre o século XVI, quando se iniciou em Portugal, até a atualidade.

Antes de nos dirigirmos à análise dos dados, é importante explicarmos que, nos termos de Auroux (2014), denomina-se de 'gramatização' o processo de descrever e instrumentar uma língua compondo seu saber metalinguístico, encontrando sua materialidade em dois pilares: a gramática e o dicionário. Neste trabalho, voltamos nosso olhar às gramáticas.

Como veremos, a gênese dos registros gramaticais e do surgimento de normas prescritas para o estudo da língua portuguesa encontra-se na obra de Fernão de Oliveira: 
Grammatica da Lingoagem Portuguesa, publicada em Portugal, no ano de 1536. Já no Brasil, a primeira publicação de uma gramática escrita por um brasileiro deu-se apenas no início do século XIX, em 1816, com o trabalho de Ignacio Felizardo Fortes, intitulado Arte de Grammatica Portugueza $a^{4}$ Contudo, com o decorrer dos séculos, fica nítida a expansão da produção desse conteúdo instrutivo, adquirindo novos comportamentos e características, conforme discutimos nos parágrafos seguintes.

\section{A compilação de um corpus da gramaticografia da língua portuguesa}

Este estudo iniciou com a compilação de um corpus de manuais gramaticais presentes nas principais instituições de ensino e pesquisa de países falantes de língua portuguesa, sendo eles: Brasil, Portugal, Angola e Moçambique. A escolha das instituições esteve diretamente ligada ao acesso ao acervo online disponível e/ou ao tamanho do centro acadêmico. No Brasil, foram consultados os acervos de 11 bibliotecas universitárias (UFU, Unicamp, Unesp, USP, UFRJ, UFMG, UFBA, UNB, UFSC) e outras duas grandes bibliotecas do Rio de Janeiro (Real Gabinete Português e Biblioteca Nacional Brasileira). Em Portugal, foram investigados os acervos das Universidades de Lisboa e Coimbra, além da Biblioteca Nacional de Portugal. $\mathrm{Na}$ Angola, nosso intuito inicial era a consulta ao acervo da universidade Agostinho Neto, maior centro universitário do país. Contudo, a instituição não conta com um acervo online de fácil acesso remoto, de modo que nossas atenções se voltaram para a Universidade Jean Piaget, onde os resultados encontrados foram mínimos. Em Moçambique, foram analisados os acervos da Universidade Eduardo Mondlane e da Biblioteca Nacional.

Ao todo, foram consultadas 19 bibliotecas físicas, com acesso remoto às informações bibliográficas do acervo. Além dessas bases de dados, outras plataformas online foram consultadas a fim de levantarmos o máximo possível de material, como é o caso do books.google.com, achirve.org, hathitrust.org, etc.

Em todas as buscas aos acervos, usamos as palavras-chave: "manual", "gramática", “compêndio", "língua", "portuguesa", "português", "norma”. Ao todo, foram catalogadas 161 publicações, separadas em duas planilhas. A primeira correspondeu ao registro das especificações textuais e extratextuais do material. Assim, conforme representa em parte a Figura 1, essa tabela foi dividida em 12 seções (i. código do item, ii. nome do autor, iii. origem do autor, iv. nome da gramática, v. páginas totais, vi. ano da primeira publicação, vii. ano da edição consultada, viii. cidade de publicação, ix. editora, x. acessibilidade ao texto, xi.

\footnotetext{
${ }^{4}$ Em 1806 o brasileiro António de Morais Silva publica, em Portugal, o Epitome da grammatica da lingua portugueza, que poderia ser considerada a primeira obra brasileira se desconsideramos o local de publicação.
} 
tipo de gramática, xii. gênero/sexo do autor). Na segunda planilha, identificamos os acervos em que cada gramática foi encontrada, isso para refletirmos sobre a circulação dos manuais.

Figura 1 - Da disposição dos dados

\begin{tabular}{|c|c|c|c|c|c|c|c|c|c|c|}
\hline I & A & B & C & D & $E$ & $F$ & G & H & 1 & J \\
\hline 1 & Código & Autor & Origem (pais) & Gramítica (nome) & Píginas (total) & Ano de publicacio (1 edicio) & Ano edifirio (consultado) & Cidade (publicacio) & Editora & Acesso \\
\hline 2 & GLP00I & $\begin{array}{l}\text { Maria Helena de } \\
\text { Moura Neves }\end{array}$ & Brasil & $\begin{array}{c}\text { Gramática de usos do } \\
\text { português }\end{array}$ & 1008 & 2000 & 2011 [ 2 ed.] & São Paulo & Ed. UNESP & Total \\
\hline 3 & GLP002 & $\begin{array}{l}\text { Ataliba Teixeira } \\
\text { de Castilho, et al }\end{array}$ & Brasil & $\begin{array}{l}\text { Gramática do Português } \\
\text { falado (Vol.8) }\end{array}$ & 3913 & 1991 & (2003) [2 ed.] & São Paulo & Ed. UNICAMP & Parcial \\
\hline 4 & GLP003 & Marcos Bagno & Brasil & $\begin{array}{l}\text { Gramática pedagógica do } \\
\text { português brasileiro }\end{array}$ & 1053 & 2011 & 2011 & São Paulo & Parábola & Total \\
\hline 5 & GLP004 & Evanildo Bechara & Brasil & $\begin{array}{l}\text { Moderna gramática } \\
\text { portuguesa }\end{array}$ & 575 & 1961 & 2009 [37 ed.] & Rio de Janeiro & $\begin{array}{l}\text { Companhia Editora } \\
\text { Nacional }\end{array}$ & Total \\
\hline 6 & GLP005 & $\begin{array}{l}\text { Mário Alberto } \\
\text { Perini }\end{array}$ & Brasil & $\begin{array}{l}\text { Gramática gerativa: } \\
\text { introduçăo ao estudo da } \\
\text { sintaxe portuguesa }\end{array}$ & 254 & 1975 & 1975 [1 ed.] & Belo Horizonte & Vigilia & Parcial \\
\hline 7 & GLP005 & $\begin{array}{l}\text { Mário Alberto } \\
\text { Perini }\end{array}$ & Brasil & $\begin{array}{c}\text { Gramática descritiva do } \\
\text { portugués }\end{array}$ & 388 & 1995 & 2005 [4 ed.] & São Paulo & Ática & Total \\
\hline 8 & GLP006 & $\begin{array}{l}\text { Ataliba Teixeira } \\
\text { de Castilho }\end{array}$ & Brasil & $\begin{array}{l}\text { Nova gramática do } \\
\text { português brasileiro }\end{array}$ & 768 & $\mathrm{R} \$ 2,010.00$ & 2012 & São Paulo & Contexto & Total \\
\hline 9 & GLP007 & $\begin{array}{c}\text { Maria Helena } \\
\text { Mira Mateus; Ana } \\
\text { Maria Brito; Inês } \\
\text { Duarte et al. }\end{array}$ & Portugal & $\begin{array}{c}\text { Gramática da lingua } \\
\text { portuguesa }\end{array}$ & 1127 & 1983 & 2003 [5 ed.] & Lisboa & Caminho & Total \\
\hline 10 & GLP008 & $\begin{array}{c}\text { Celso Ferreira da } \\
\text { Cunha }\end{array}$ & Brasil & $\begin{array}{l}\text { Gramática da lingua } \\
\text { portuguesa }\end{array}$ & 655 & 1979 & 1980 [2 ed.] & Rio de Janeiro & Fename & Nulo \\
\hline 11 & GLP009 & $\begin{array}{l}\text { Celso Ferreira da } \\
\text { Cunha }\end{array}$ & Brasil & Gramática de base & 370 & 1981 & 1981 [2 ed.] & Rio de Janeiro & Fename & Nulo \\
\hline
\end{tabular}

Fonte: corpus compilado pelos autores.

Concluída a busca e a identificação desses materiais nos respectivos acervos eletrônicos, iniciamos a procura pelas versões impressas ou digitalizadas desses manuais a fim de garantirmos a acessibilidade ao texto. Esse objetivo se deu com o fim de alcançarmos uma análise mais consistente, além de permitir a composição de um corpus para futuros estudos sobre a gramaticografia da língua portuguesa. Considerando a acessibilidade ao texto, os itens compilados foram divididos em:

- Acesso total: manual que permite o acesso completo ao texto, seja eletrônico ou fisicamente.

- Acesso parcial: manual que apenas permite o acesso a partes do texto, seja de um capítulo ou do sumário.

- Acesso nulo: manual sem qualquer possibilidade de acesso ao texto.

Conforme apresenta o Gráfico 1, do total de itens encontrados e registrados, o acesso 'total' correspondeu a 66 das 161 gramáticas, totalizando 41\% dos itens. A acesso 'parcial' correspondeu a 9 das 161 gramáticas, totalizando 6\% de acesso. Por fim, o acesso 'nulo' correspondeu a 86 das 161 gramáticas, totalizando 53\% do acervo. Em outros termos, o acesso ao texto (em sua totalidade ou parcialidade) é apenas possível em quase metade das 
obras encontradas (75 obras/47\%). Esse material poderá servir de apoio e de embasamento para futuros estudos que se atentem a outras questões de gramatização, contribuindo, por exemplo, para os estudos de Norma Linguística, de Historiografia Linguística e de Ensino do Português.

Gráfico 1 - Da acessibilidade às gramáticas catalogadas

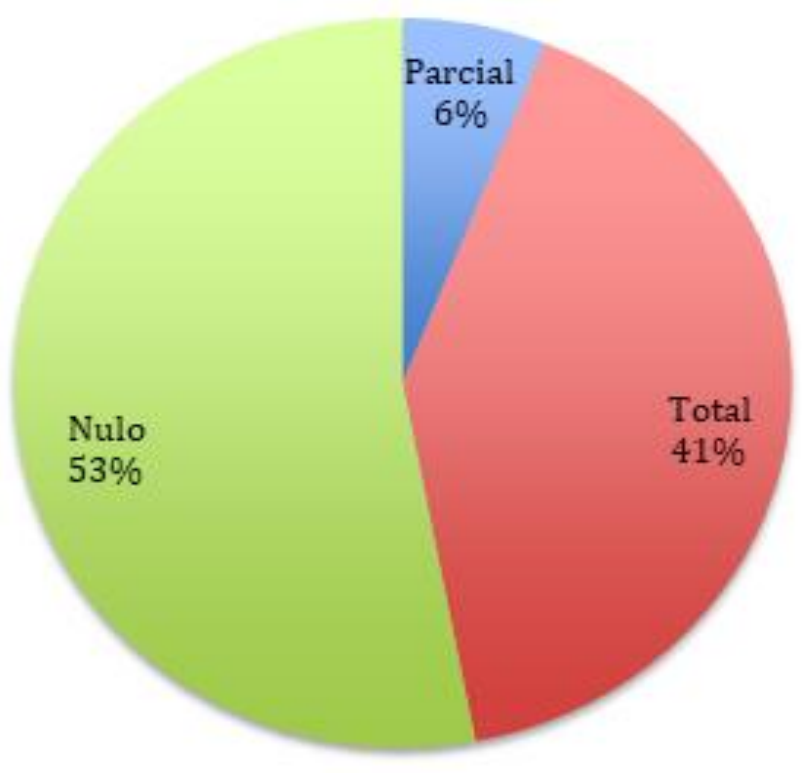

Fonte: corpus compilado pelos autores.

Conforme vimos na Figura 1, os dados levantados ao longo desta pesquisa foram agrupados e refinados segundo os diferentes fatores controlados, gerando dados relevantes para o conhecimento da história e da formação da gramaticografia da língua portuguesa. Desse modo, a partir da próxima seção, analisamos os pontos mais relevantes para o objetivo deste estudo, estabelecendo cruzamentos entre os fatores sempre que necessário para obtermos uma informação mais refinada e relevante para o estudo da gramaticografia da língua portuguesa.

\section{Investigando a gramaticografia do português}

Dos fatores controlados e analisados, certamente o tempo (ano de publicação) é o que mais tem a nos revelar, especialmente com base no cruzamento com outros fatores - como fazemos ao longo desta discussão. Conforme sintetiza o gráfico II, nota-se que o início tímido da produção gramaticográfica da língua portuguesa parece estender-se até o século XVIII. Assim, o surgimento da gramática na língua portuguesa ocorre no século XVI, marcada por apenas duas publicações encontradas: a primeira de Fernão Oliveira, publicada em 1536, e a 
segunda de João de Barros, publicada em 1540. Conforme ainda sintetiza o Gráfico 2, nossa busca não encontrou nenhum material referente ao século XVII ${ }^{5}$ e apenas cinco gramáticas identificadas como pertencentes ao século XVIII.

É, contudo, a partir do século XIX, paralelamente ao despontamento dos estudos linguísticos, que encontramos o grande salto na produção de gramáticas em língua portuguesa - comportamento que se manteve na mesma intensidade no século XX. Por sua vez, os anos iniciais do século XXI apontam uma tendência de maior incremento, posto que já apresenta metade da produção verificada nos dois séculos anteriores em apenas duas décadas.

Gráfico 2 - Da produção de gramáticas ao longo do tempo

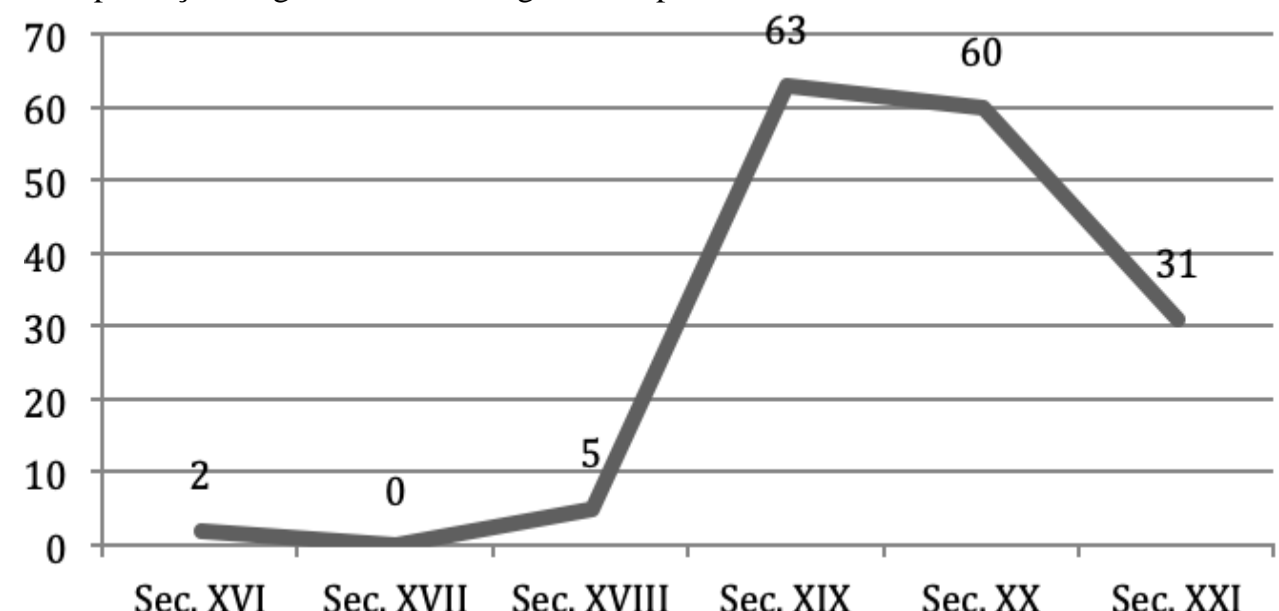

Fonte: corpus compilado pelo autor

Língua falada em nove países, naturalmente a gramatização do português não pode estar limitada a apenas um deles. Mesmo encontrando alguns países com participação mais intensa na produção de gramáticas, é possível estabelecer laços com outras nações lusófonas.

Assim, no que se refere ao espaço em que se desenvolveu a gramatização da língua portuguesa, dois fatores contribuem para nosso estudo: (i) a origem do autor e a (ii) cidade de publicação do material. Tendo em vista que essas informações não dependem do acesso integral ao texto, também foi possível identificar esses dados em todas as gramáticas compiladas.

\footnotetext{
${ }^{5}$ Identificamos os trabalhos de Amaro de Roboredo (VOLPE, 2016), no entanto, observamos que seus trabalhos estavam mais voltados à língua latina ou à proposição de uma gramática universal, pelo que não o tratamos neste estudo.
} 
Gráfico 3 - Da nacionalidade de origem dos autores

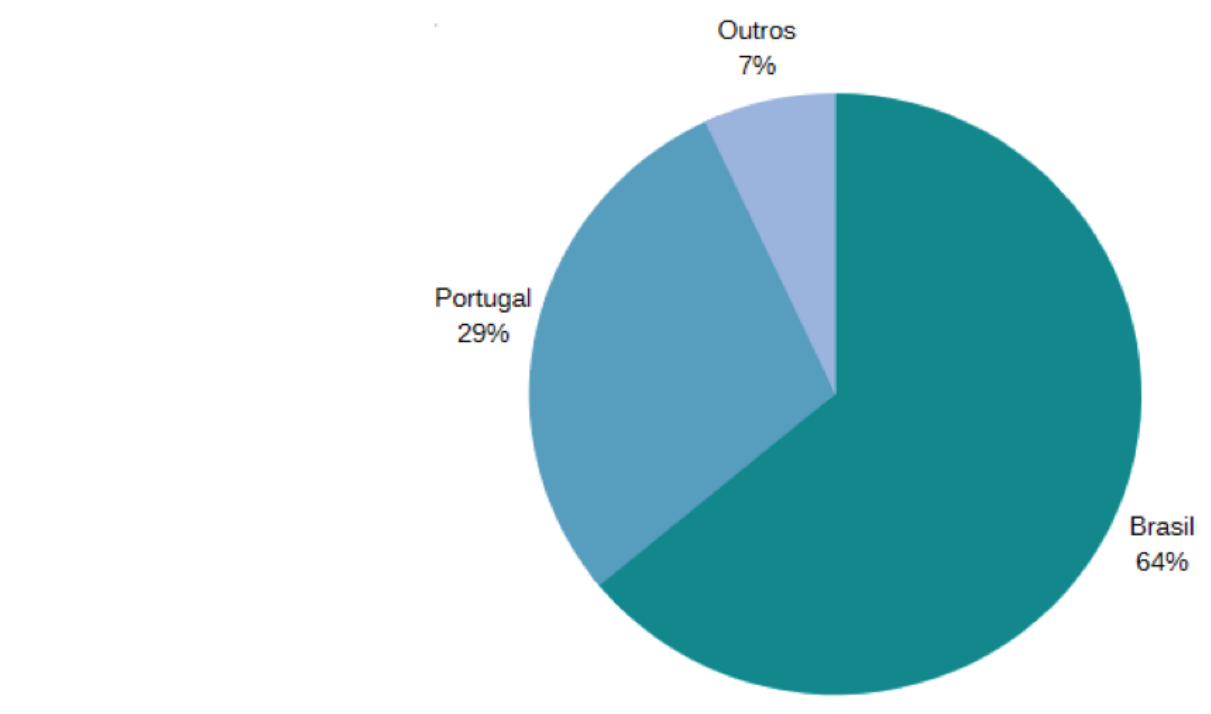

Fonte: corpus compilado pelos autores.

Atendo-se ao fator "origem do autor", o Gráfico 3 revela-nos que, em porcentagem, a distribuição dos materiais compilados em relação à origem da autoria se dá da seguinte forma:

- Brasil destaca-se com a maior representação de gramáticos por deter a autoria de quase 64\% (103 de 161) do total, o que coloca o país como o principal contribuidor em termos quantitativos para a tradição gramaticográfica da língua portuguesa.

- Portugal aparece em segundo lugar com 29\% (47 de 161) do total de gramáticas compiladas, colocando o país em lugar de destaque - especialmente respeitando as dimensões geossociais de Brasil e Portugal.

- Vale destacar duas parcerias feitas entre autores brasileiros e portugueses, trata-se da Nova gramática do português contemporâneo (1985) - de Celso Ferreira da Cunha e Lindley Cintra - e da Gramática da língua portuguesa (1995) - de Mário Vilela e Ingedore Koch.

Em outros termos, juntos, autores do Brasil e de Portugal se responsabilizaram pela produção de quase 95\% (152 de 161) dos itens compilados, o que coloca as duas nações em lugar de referência na produção da norma gramatical. Vale destacar que nenhuma gramática de autoria angolana foi encontrada em nossa busca pelos acervos e apenas um material teve autoria moçambicana: a Gramática portuguesa, de José Maria Relvas, publicada em 1927 pela editora Livraria Leia, em Maputo.

Considerando aquelas publicações cujos autores são procedentes de países não lusófonos, encontramos oito gramáticas (5\%), das quais seis tiveram autoria de origem espanhola e duas da tradição francófona. Vale destacar que cinco das gramáticas de origem espanhola são voltadas ao ensino de português como língua estrangeira - todas do século XXI 
-, e as demais (espanhola, francesa e suíça) a uma descrição tradicional mais geral e menos aplicada - ressalta-se entre elas a Nova grammatica analytica da lingua portugueza, do suiço Charles Adrien Olivier Grivet, publicada em 1881, no Rio de Janeiro.

O cruzamento dos dados referentes à origem dos autores com o ano de publicação das obras coloca em evidência que, ao menos no corpus compilado, Portugal deteve completo domínio sobre a produção gramatical em língua portuguesa até o início do século XIX, quando surgem as primeiras gramáticas escritas por brasileiros. Apesar de em 1806 ser publicada em Portugal o Epitome da grammatica da lingua portugueza, do filólogo brasileiro António de Morais Silva, é apenas em 1816 que se publica a primeira gramática no Brasil, trata-se da Arte de Grammatica Portugueza, de Ignacio Felizardo Fortes.

Ao observarmos o crescimento de autores brasileiros na participação da gramaticografia da língua portuguesa ao longo do tempo, vemos, como sintetiza o Gráfico 4, que já no século XIX foi possível encontrar um maior volume de publicações brasileiras, comportamento que se manteve até os dias atuais - com incremento no percentual de diferença (range) entre as autorias portuguesas e brasileiras, inicialmente limitada a $22 \%$ (no séc. XIX) e terminando em $67 \%$, no primeiro quarto do século XXI. Esses números evidenciam o potencial brasileiro na normatização e na descrição da língua portuguesa desde o século XIX.

Ainda, há o crescimento de publicações cuja autoria pertence a países não lusófonos. No corpus compilado, essa produção supera a de Portugal no século XXI e todas se relacionam a gramáticas voltadas ao ensino do português para estrangeiros.

Gráfico 4 - Da relação da origem dos autores ao longo do tempo

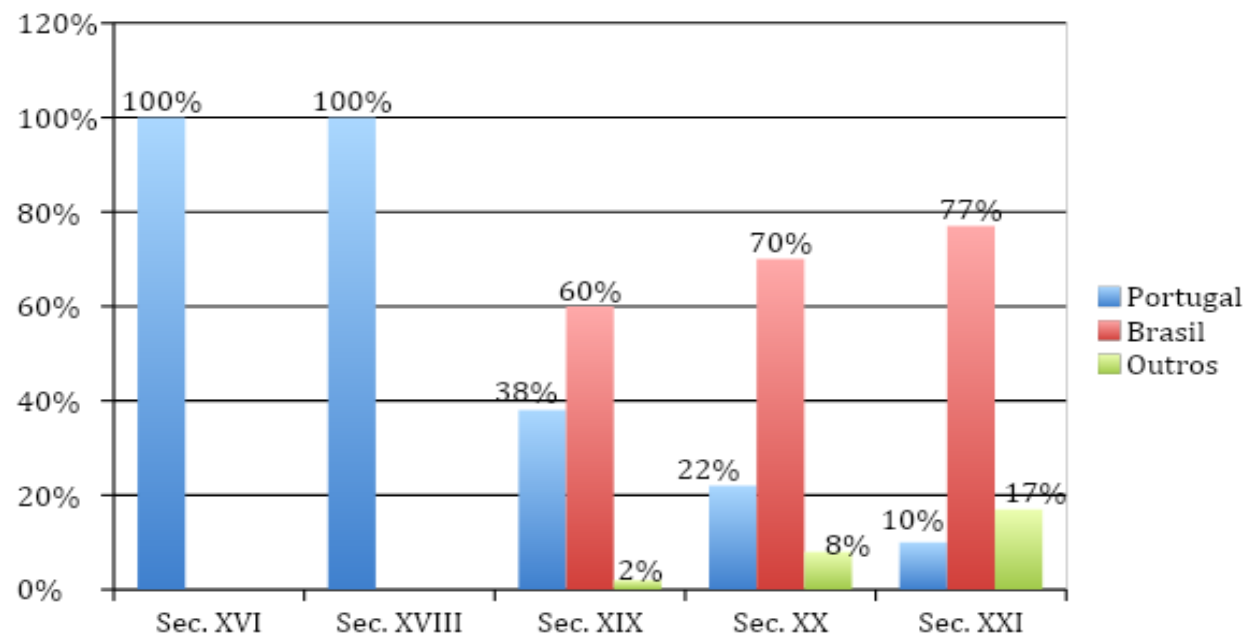

Fonte: corpus compilado pelos autores. 
Finalmente, o local de edição das obras compiladas foi outro fator controlado e que julgamos pertinente para conhecermos a dimensão espacial da normatização em língua portuguesa. Já sabemos que o maior mercado editorial é brasileiro, posto que das 161 gramáticas, 106 foram publicadas no Brasil. Destacam-se o Rio de Janeiro e São Paulo como as cidades com maior número de edições, 37 e 45, respectivamente. No Nordeste, São Luís do Maranhão destaca-se com 7 publicações, todas ocorridas no século XIX e no início do século XX. De Portugal, encontramos 50 registros, com destaque a Lisboa, como 23 deles, Porto e Coimbra, com 13 e 11 edições, respectivamente. Outras cidades nesses países e em outros (Maputo, Paris, Madri, Barcelona) também apresentam publicações, com quantidade muito mais baixa.

Outro fator controlado que está relacionado à autoria é o gênero/sexo dos escritores. Por se tratar de uma abordagem que envolve um recorte diacrônico relativamente extenso, no qual, nos primeiros séculos, encontram-se os homens em lugar privilegiado de produção de conhecimento e a mulher à margem, naturalmente o maior percentual de publicação esteve associado ao sexo masculino. Contudo, o cruzamento desse fator com a variável "ano de publicação" permite analisar quando se deu a inserção do público feminino nessa atividade, bem como o papel que ocupa na atualidade.

Uma análise geral dos dados explicita que os homens são responsáveis pela autoria de 86\% (139 de 161) dos escritos, compartilham com mulheres a escrita de 10 gramáticas (6\%) e apenas 8\% (12 de 191) das gramáticas têm autoria exclusiva de mulheres. Em acréscimo, o lugar de exclusão da mulher parece não se limitar a esse percentual ou ao passado distante que envolve este estudo, pois a primeira gramática de autoria feminina encontrada data da segunda década do século XX, trata-se da obra Lições de Português, de Noêmia Carneiro, publicada em 1957, no Rio de Janeiro. Ainda assim, apenas cinco gramáticas de autoria feminina foram publicadas no século $\mathrm{XX}$, as sete restantes distribuem-se entre as primeiras décadas do século XXI.

Esses dados trazem à discussão uma questão importante e que retrata a exclusão do gênero feminino ainda nos dias atuais. É indiscutível que ao longo de nossa formação escolar nas últimas décadas, a maior parte de nossos professores e autoridades em sala de aula são mulheres. Desse modo, devemos nos questionar por que somente no século XXI é que essas figuras começam a se sustentar na produção de manuais linguísticos - ainda, é claro, com um percentual que aponta haver ainda certa limitação. Além disso, cabe pensar sobre a norma linguística criada até então exclusivamente por gramáticos do gênero masculino, pois certamente a concepção de língua abordada em seus manuais estará atravessada por sua 
identidade social e pelo uso que faz da linguagem - posto que, conforme têm demonstrado os estudos da Sociolinguística, a norma linguística também é regulada pelo gênero/sexo do falante.

Finalmente, outras análises quantitativas resultantes de dados extratextuais controlados dizem respeito, primeiramente, a autores com maior quantidade de obras publicadas, categoria em que se destacam Celso Cunha, com seis diferentes obras, Evanildo Bechara, com quatro, e Vicente Masip e Manuel Said Ali, ambos com três gramáticas. A segunda informação diz respeito às gramáticas mais recorrentes nos 19 acervos de bibliotecas consultados. Em primeiro lugar, está a Gramática da linguagem portuguesa, de Fernão de Oliveira, presente em cinco bibliotecas (duas brasileiras, duas portuguesas e uma moçambicana). Encontrada em quatro bibliotecas, a Nova Gramática do português contemporâneo, de Celso Ferreira da Cunha e Lindley Cintra também se destaca nessa categoria. A obra propriamente descritiva com circulação aparentemente maior foi a Gramática do português falado, coordenada pelo Professor Ataliba Teixeira de Castilho com outros linguistas brasileiros. Essa coleção também foi encontrado em quatro bibliotecas, divididas entre Brasil e Portugal.

Esse cenário descrito parece indicar não apenas a contribuição de Celso Cunha para a tradição gramatical da língua portuguesa - dada a grande produtividade de gramáticas e circulação de sua produção em três continentes -, mas também a importância dada à obra fundadora da gramaticografia lusófona (a Gramática da linguagem portuguesa, de Fernão de Oliveira) e a relevância da inserção das reflexões linguísticas contemporâneas para a proposta de manuais descritivos - como o projeto coordenado pelo professor Ataliba de Castilho (Gramática do português falado).

Por último, e talvez mais importante, cabe-nos refletir sobre a tipologia desses manuais, ou seja, verificar quais características, objetivos e público alvo as gramáticas de língua portuguesa foram adquirindo ao longo do tempo. Para tanto, começamos por delinear cinco principais categorias tipológicas de gramáticas a que recorremos em nossa análise:

i. Gramática Tradicional: seu objetivo concentra-se nas normas do bem falar e escrever, estipulando uma espécie de lei que regula o uso da língua. Considera "erro" qualquer uso concreto existente em variedades que fujam dos regulamentos de suas páginas (TRAVAGLIA, 2002). Segundo Vieira (2016, 2018), a gramática normativa tomará a frase como unidade máxima de análise e se valerá de um "aparato categorial conceitual e terminológico comum, fixo e tanque".

ii. Gramática Descritiva: resulta do amadurecimento da Linguística, envolve um projeto em que linguistas tentam registrar o funcionamento da língua por ela 
mesma, com valoração subjetiva de uma variedade sobre outra e apoiando-se em critérios teóricos e metodológicos objetivos da Linguística para proceder a sua descrição. Trata-se, portanto, de um projeto de descrição de uma norma normal, geralmente tratada como a "norma culta". Vieira $(2016,2018)$ explica que o público principal dessa gramática costuma ser "o leitor especializado: o linguista, o professor de português, o estudante de letras".

iii. Gramática Histórica: estuda a evolução dos diversos fatos da língua desde a sua origem até a época presente, ou seja, analisa a evolução histórica de uma língua. Também podemos entender como sendo aquela que estuda uma sequência de fases evolutivas de um idioma (BECHARA, 1968).

iv. Gramática Escolar: especificamente destinada para o uso em sala de aula, é voltada ao ensino em um contexto de aprendizado das normas que regem a língua. Neste trabalho, foi subdividida em três tópicos: a "normativa" (que obedece aos padrões tradicionais), a "descritiva" (uma modalidade recém inserida em sala de aula, pautada pela gramática descritiva e atenta a um ensino que busca combater o preconceito linguístico) e para "estrangeiros" (que busca ensinar o idioma para os não nativos).

Quando aplicada aos dados compilados, essa tipologia revelou - como nos mostra o Gráfico 5 - que a Gramática Escolar parece ocupar lugar singular e norteador na produção de gramáticas na tradição normativa da língua portuguesa, isso porque esse tipo corresponde a mais da metade das gramáticas encontradas (55\%/ 90 itens). Por sua vez, a Gramática Tradicional foi verificada em 43 itens (28\%), enquanto a Gramática Descritiva apenas foi identificada em 20 dos manuais (12\%). Em último lugar, encontram-se as gramáticas do tipo histórico, com apenas 8 itens $(5 \%)$.

Gráfico 5 - Da tipologia das gramáticas

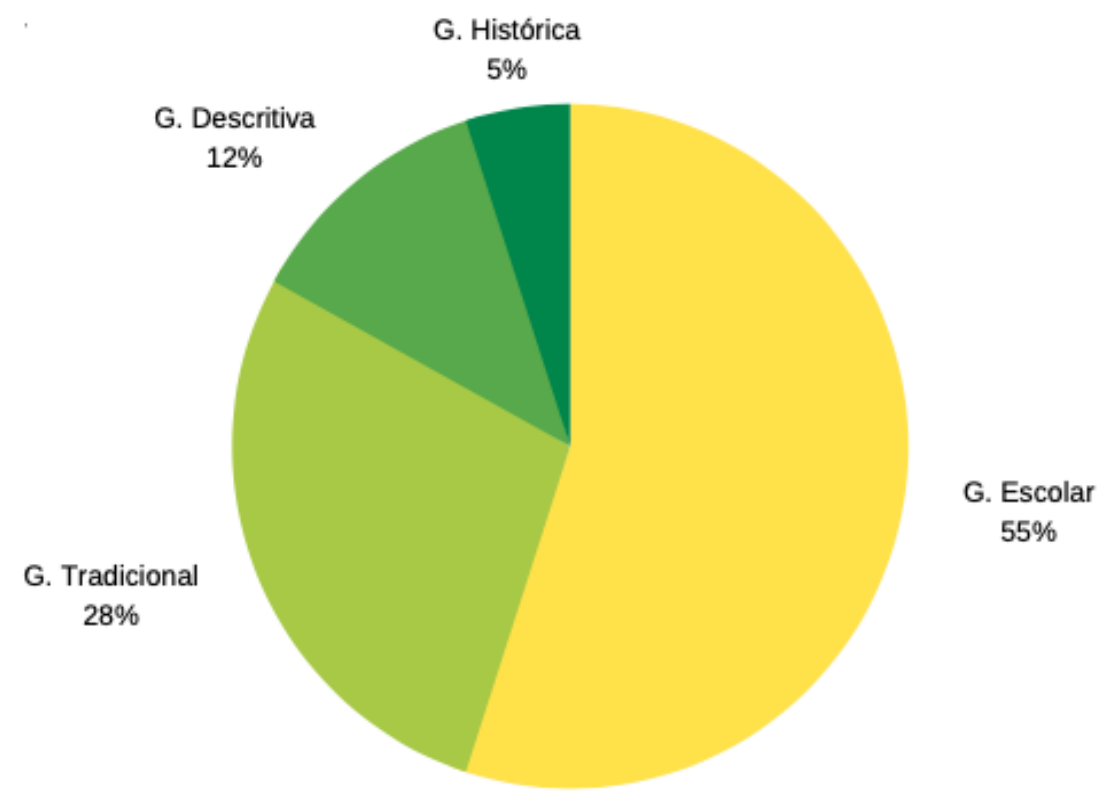

Fonte: corpus compilado pelos autores. 
Essas informações quantitativas colocam em evidência o caráter pedagógico que se associou à gramaticografia das línguas românicas desde seu início - como pontua Auroux (2014) e que, como não poderia deixar de ser, parece se evidenciar também na língua portuguesa. É pertinente observarmos que a Gramática Tradicional contribui com essa preocupação doutrinária, posto que traz entre seus objetivos um caráter pedagógico (VIEIRA, 2018). Essa proximidade entre o tipo escolar e tradicional se torna ainda mais evidente se consideramos uma subcategorização das gramáticas escolares - sintetizada no Gráfico 6:

Gráfico 6 - Da subcategorização da gramática escolar

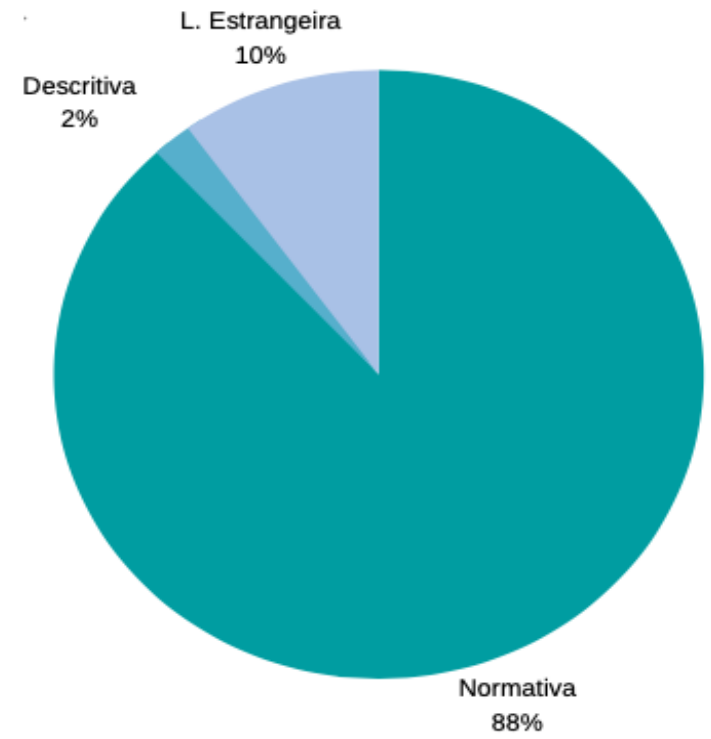

Fonte: corpus compilado pelos autores.

Conforme mostra o gráfico, $88 \%$ das gramáticas escolares (79 das 90) assumem um viés normativo e compatível, portanto, com a Gramática Tradicional. Por outro lado, apenas duas gramáticas (2\%) assumem um diálogo com uma abordagem descritiva - todas publicadas na última década ${ }^{6}$-; o que evidencia um campo ainda carente de atenção dos estudos gramaticógrafos do português. Finalmente, $10 \%$ (7) dos manuais escolares assumem um objetivo de ensino de português para estrangeiros, área de produção gramaticográfica que parece estar em ascensão, haja vista que quase todos os itens encontrados começam a ser publicados no fim da década passada.

\footnotetext{
${ }^{6}$ Os únicos manuais desse tipo encontrados foram (i) a "Pequena Gramática do Português Brasileiro", de Ataliba Teixeira de Castilho e Vanda Maria Elias, publicada em 2011; (ii) Gramática de bolso do português brasileiro, de Marcos Bagno, publicada em 2014.
} 
Para compreendermos melhor os dados referentes às tipologias gerais de classificação das gramáticas (Gráfico 5), é imprescindível cruzar essas informações com o fator tempo. Para tanto, fundamentamo-nos nos dados expostos no Gráfico 7:

Gráfico 7 - Da tipologia das gramáticas em relação ao tempo

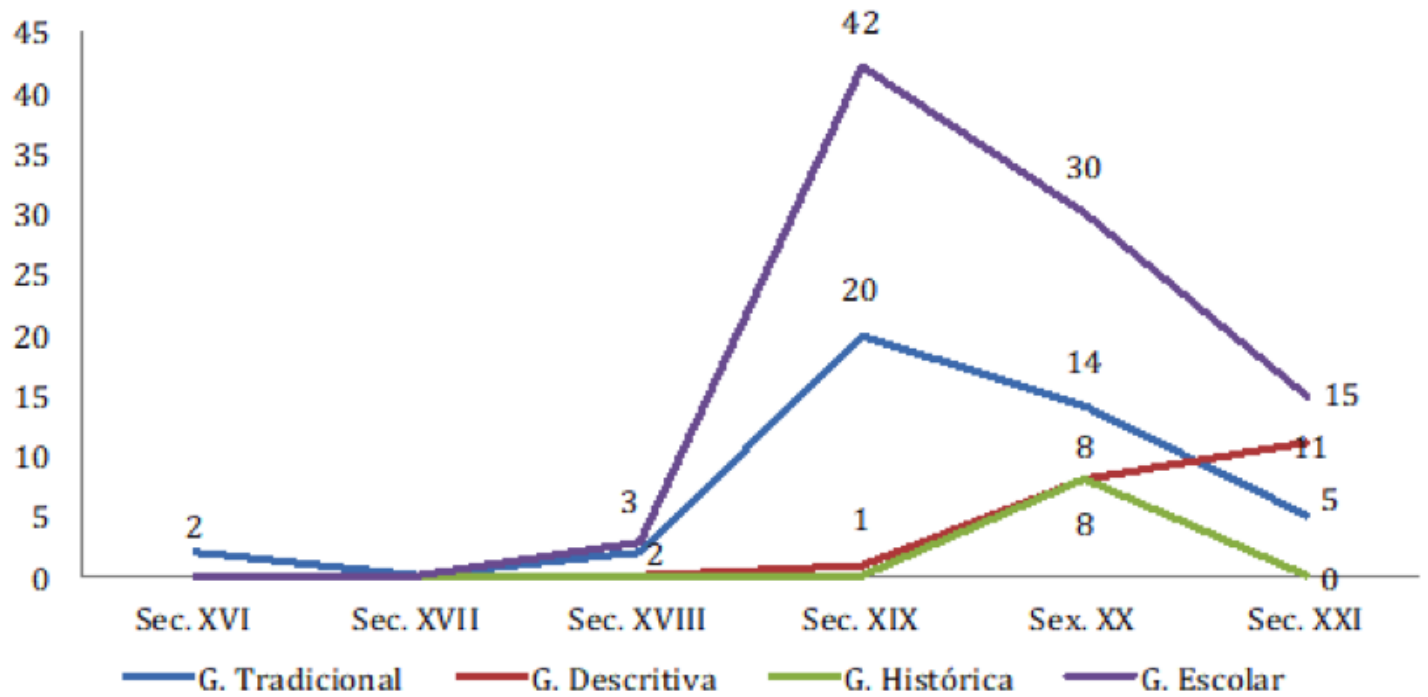

Fonte: corpus compilado pelos autores.

A tradição gramatical em língua portuguesa tem como porta de entrada, no Séc. XVI, a Gramática Tradicional, arrastando-se desde então como modelo recorrente, com oscilações, até os dias atuais. Por sua vez, a gramática escolar, amparada nos pressupostos teóricos da abordagem tradicional e aplicando-os ao ambiente educacional, tem sua primeira manifestação para falantes de português encontrada no início do século XVIII, na obra de Jerónimo Contador de Argote, intitulada Regras da Lingua Portugueza, Espelho da Língua Latina, ou disposição para facilitar o ensino da lingua Latina pelas regras da Portugueza, publicada em 1725, em Lisboa.

Contudo, encontramos uma obra anterior, voltada ao ensino de língua estrangeira através do método comparativo, em que se confrontam o português e o inglês. Trata-se do manual de Jacob de Castro Sarmento, a Grammatica anglo-lusitanica: or a short and compendious system of an english and portuguese grammar, publicada em Lisboa no ano de 1702.

Ainda sobre o modelo escolar, é pertinente destacarmos como seu crescimento é acentuado no século XIX, alçando no corpus compilado 42 exemplares e ultrapassando os demais tipos de gramática. A superioridade quantitativa da gramática escolar continua nos demais séculos. Contudo, parece que é apenas no século XXI que esse tipo começa a ganhar 
novas dimensões, ao encontrarmos novos exemplares voltados ao ensino de português como língua estrangeira e propostas inovadoras, em que se deixa a referência exclusiva da gramática normativa e se inicia do diálogo com a gramática descritiva - conforme pontuado no Gráfico 6.

Esse diálogo com a gramática descritiva resulta do amadurecimento dessa tipologia, que no corpus compilado encontrou seu embrião na Grammatica descriptiva, de Maximino Maciel, publicada em 1844, no Rio de Janeiro. A sedimentação, contudo, da gramática descritiva ocorre no fim do século XX, com oito itens catalogados. Na sequência, observa-se um maior crescimento do tipo descritivo no século XXI, quando foram registrados 11 itens. Evidentemente, que esse crescimento resulta do amadurecimento e progresso dos estudos linguísticos nas comunidades lusófonas, principalmente no Brasil.

Por fim, todas as gramáticas históricas compiladas datam do século $\mathrm{XX}$, sendo a primeira encontrada a Compêndio de gramática histórica portuguesa, de José Joaquim Nunes, publicada em Lisboa, em 1919.

\section{Considerações finais}

A gramática vai além de um mero apoio à aula de língua portuguesa, vai à frente ao registrar a língua e apresentar-se como meio indireto de entender a sociedade e seu funcionamento. Mais diretamente, a gramática pode ainda nos revelar o processo histórico de formação da língua ao longo dos séculos. Nessa direção, o desenvolvimento do presente estudo resultou no contato com 161 gramáticas de língua portuguesa e permitiu mapear, catalogar e analisar, através de características textuais e extratextuais, o comportamento da gramaticagrafia de língua portuguesa, visando traçar suas características ao longo do tempo e sua relação com a sociedade. Desse modo, o compilado dos dados constituiu mais um passo para o estudo da norma linguística e de seu registro.

As informações sobre localidade foram capazes de demonstrar que mesmo sendo o idioma de uma variedade de países, a principal parcela da produção gramatical encontra-se dividida entre Brasil e Portugal, sendo o último pioneiro nesse tipo de material, enquanto o Brasil traz o maior número de gramáticas e de autores, conforme dados explorados.

Já o fator relacionado ao ano de publicação traz uma visualização histórica sobre como seu deu essa produção gramatical, tendo seu principal recorte entre os séculos XIX e XXI. Já a tipologia, revelou que a gramática tida como escolar é a mais expressiva, assim como a autoria masculina que se faz quase que unânime. Tudo isso em conjunto ajuda-nos a medir a 
importância dada à língua através do tempo e a pertinência contida em seu registro para uso social e escolar, seja enquanto língua materna ou estrangeira.

Nosso estudo vem como um ponto de partida para o entendimento da gramaticografia portuguesa e seu desenvolvimento através dos séculos, abrindo-se ainda à possibilidade de estudos mais aprofundados que possam vir a complementar o corpus compilado ou até mesmo a caracterização do material aqui já presente.

\section{Referências}

ALEONG, S. Normas linguísticas, normas sociais: uma perspectiva antropológica. In: BAGNO, M. Norma linguística. São Paulo: Ed. Loyola, 2001. p. 145-174.

BAGNO, M. Língua, Linguagem e Linguística: pondo os pontos nos ii. São Paulo: Parábla Editorial, 2014.

BECHARA, E. Curso Moderno de Português. 2 ed. São Paulo. Companhia Nacional, 1968.

AUROUX, S. A revolução tecnológica da gramatização. 3. ed. Trad. Eni Puccinelli Orlandi. Campinas: Editora da Unicamp, 2014.

COSERIU, E. Sistema, norma y habla. In: COSERIU, E. Teoría del lenguaje y lingüística general. 3. ed. Madrid: Gredos, 1962.

TRAVAGLIA, L. C. Gramática e interação: uma proposta para o ensino de gramática no $1^{\circ}$ e $2^{\circ}$ graus. São Paulo: Cortez, 2002.

VIEIRA, F. E. Gramatização brasileira contemporânea do português: novos paradigmas? In: VIEIRA, F. E. FARACO, C. A. Gramáticas brasileiras: com a palavra, os leitores. São Paulo: Parábola Editorial, 2016. p. 19-69.

VIEIRA, F. E. A gramática tradicional: história crítica. São Paulo, 2018.

VOLPE, A. S. Séc XVII - Gramáticas de Amaro de Roboredo e de Port-Royal. Verbum, n. 9, p. 69-78, 2016. 


\section{Sobre os autores}

Mariane Rezende Melazo (Orcid iD: https://orcid.org/0000-0003-3203-8022)

Graduada em Letras - Português e Literatura Portuguesa pela Universidade Federal de Uberlândia (UFU). Foi bolsista CNPq de Iniciação Científica.

Leandro Silveira de Araujo (Orcid iD: https://orcid.org/0000-0001-8518-1266)

Doutor e mestre em Linguística e Língua Portuguesa pela Universidade Estadual Paulista (UNESP); graduado em Letras - Português/Espanhol pela mesma instituição. É professor no Instituto de Letras e Linguística, no Programa de Pós-Graduação em Estudos Linguísticos e no Mestrado Profissional em Letras da Universidade Federal de Uberlândia (UFU).

Recebido em agosto de 2020.

Aprovado em outubro de 2020. 